\title{
Health-seeking behaviour of mentally ill patients in Enugu, Nigeria
}

Aniebue Patricia Nonye, MB BS, FWACP

Ekwueme Christiandolus Oseloka, MB BS, FMCPH

Department of Community Medicine, University of Nigeria Teaching Hospital, Enugu, Nigeria

\begin{abstract}
Aim. To determine the health-seeking behaviour of mentally ill patients in Enugu, Nigeria.

Design. A consecutive recruitment of 397 patients receiving treatment at the neuropsychiatric hospital in Enugu was done. Using a structured questionnaire, information was obtained from the respondents including their socio-demographic characteristics, their knowledge of the cause of their mental illness, and the treatment that they first employed, with their reasons for doing so.

Results. The age range of the respondents was $15-75$, with a mean of 31.6 years (SD \pm 11 years). Two hundred and twentythree $(56.2 \%)$ respondents were male and 174 (43.8\%) were female. Treatment options first employed by respondents were prayer houses (34.5\%), followed by psychiatric hospital (32\%). The main reasons for the treatment options employed were confidence of cure at the place of treatment $(46.3 \%)$ ignorance of the existence of a mental health service (14.6\%), and the belief that the mental condition was not amenable to orthodox treatment (8.1\%). Patients' perceptions of the cause of their ailment most commonly revealed a belief in demonic and spiritual forces. Gender, educational status, attributing of the mental illness to a rational cause, and living in an urban area were significantly associated with the employment of specialist care as the first treatment option.

Conclusion. Misconceptions regarding the cause of mental illness still abound among mentally ill patients in Nigeria. Consequently, psychiatric consultation is not usually initially employed, especially in rural areas. Community health education aimed at changing misconceptions, and the integration of mental health services into primary health care services, is advocated.
\end{abstract}

Awareness of mental illness as a significant cause of morbidity is increasing worldwide. This awareness has increased with the steady decline of morbidity due to nutritional disorders, communicable diseases and other forms of physical illness, especially in countries undergoing epidemiological transition Ithese are countries where epidemiological attention shifts from declining communicable diseases, malnutrition and problems associated with pregnancy and childbirth, to chronic noncommunicable diseases which are then the dominant public health problems).' A significant disease burden is attributable to mental illness globally. Out of the top 10 leading causes of disability throughout the world, 5 are psychiatric illnesses. ${ }^{2}$ According to the World Health Organization (WHO), mental illnesses account for $11.5 \%$ of the global burden of disease - a figure that is projected to increase to $15 \%$ by 2020 . Worldwide, 340 million people suffer from mental illnesses, with the majority living in the developing world. ${ }^{3}$

In Nigeria, the prevalence of mental illness is reported at $20 \%{ }^{4}$ With a population of 140 million and less than 100 psychiatrists, the ratio of psychiatrists to population is 1:1 $400000 .^{5}$ This is a long way from the ideal; the equivalent figure for Europe is 1:1 000. These figures imply that many people who need psychiatric consultation and management hardly have access to it, with the likelihood of poor disease outcomes in such instances. As the health-seeking behaviour of patients plays a pivotal role in the outcome of any disease, it is important to understand the treatment options employed by mentally ill patients and their reasons for doing so. This study was conducted to establish the treatmentseeking behaviour of patients suffering from mental illnesses in south-eastern Nigeria. These findings may inform policymakers on how best to utilise the mental health services available.

\section{Materials and methods}

A cross-sectional study was conducted at the neuropsychiatric hospital in Enugu. It is one of eight psychiatric hospitals established by the government, and is a specialist institution established in 1970 to care for casualties from the Nigerian civil war of 1967 - 1970. Enugu was the former capital of the southeastern region of Nigeria. The hospital serves the five states in the region and beyond. The people of the region are ethnically Ibo and are deeply religious; the predominant religion is Christianity, with some adherents to traditional and Islamic forms of religion. Most of the working population is self-employed while the balance engage in farming or are employed by the government.

The neuropsychiatric hospital has two male wards and two female wards, and it is policy that at least one close relation stays with 


\begin{tabular}{|c|c|c|}
\hline Variable & $N$ & $\%$ \\
\hline \multicolumn{3}{|l|}{ Gender } \\
\hline Male & 223 & 56.2 \\
\hline Female & 174 & 43.8 \\
\hline \multicolumn{3}{|l|}{ Age (yrs) } \\
\hline$<20$ & 40 & 10.1 \\
\hline $20-29$ & 180 & 45.3 \\
\hline $30-39$ & 99 & 24.9 \\
\hline $40-49$ & 39 & 9.8 \\
\hline $50-59$ & 25 & 6.3 \\
\hline$>60$ & 14 & 3.6 \\
\hline \multicolumn{3}{|l|}{ Marital status } \\
\hline Single & 276 & 69.5 \\
\hline Married & 96 & 24.2 \\
\hline Separated/divorced & 8 & 2.0 \\
\hline Widowed & 17 & 4.3 \\
\hline \multicolumn{3}{|l|}{ Educational attainment } \\
\hline No formal education & 29 & 7.3 \\
\hline Primary education & 87 & 21.9 \\
\hline Secondary education & 161 & 40.6 \\
\hline Tertiary education & 120 & 30.2 \\
\hline \multicolumn{3}{|l|}{ Area of residence } \\
\hline Urban & 248 & 62.5 \\
\hline Rural & 149 & 37.5 \\
\hline
\end{tabular}

each patient from admission. Daily clinics are run by specialist psychiatrists. Ethical approval for this study was obtained from the ethics committee of the University of Nigeria Teaching Hospital, Enugu. Informed verbal consent was also obtained from each patient or relative before recruitment into the study. A structured pre-tested questionnaire was used by medical students specially trained for the survey, to collect data from patients or their relatives. The questionnaire was developed by the authors and pre-tested on patients attending another tertiary hospital in the locality. Questions identified as ambiguous were rephrased.

Information obtained included socio-demographic characteristics of the patients, sources of care employed by the patients and their reasons for doing so, and their beliefs regarding psychiatric ailments. Data entry and analysis were done using the SPSS statistical package, and statistical calculations were done at a $5 \%$ significance level.

\section{Results}

Of 416 questionnaires distributed, 397 were completed and returned, giving a response rate of $95.4 \%$. Two hundred and

\begin{tabular}{|c|c|c|}
\hline & $N$ & $\%$ \\
\hline \multicolumn{3}{|l|}{ Place of first visit } \\
\hline Prayer house & 137 & 34.5 \\
\hline Psychiatric hospital & 127 & 32.0 \\
\hline Private clinic & 63 & 15.9 \\
\hline Traditional healer & 54 & 13.6 \\
\hline Patent medicine vendor & 16 & 4.0 \\
\hline \multicolumn{3}{|l|}{$\begin{array}{l}\text { Reasons for choice of place of } \\
\text { first visit }\end{array}$} \\
\hline \multicolumn{3}{|l|}{ Confident of cure } \\
\hline \multirow{2}{*}{$\begin{array}{l}\text { Ignorance of existence of a } \\
\text { psychiatric hospital }\end{array}$} & 184 & 46.3 \\
\hline & 58 & 14.6 \\
\hline $\begin{array}{l}\text { Thought illness not amenable } \\
\text { to orthodox care }\end{array}$ & 32 & 8.1 \\
\hline Fear of stigmatisation & 20 & 5.0 \\
\hline Proximity & 14 & 3.5 \\
\hline Lower cost & 12 & 3.1 \\
\hline Long waiting time/staff attitude & 10 & 2.5 \\
\hline Not stated & 67 & 16.9 \\
\hline \multicolumn{3}{|l|}{$\begin{array}{l}\text { Reason for eventual visit to } \\
\text { psychiatric hospital }\end{array}$} \\
\hline Advice by friends/relatives & 178 & 44.8 \\
\hline No improvement & 72 & 18.2 \\
\hline Referral by health staff & 83 & 20.9 \\
\hline Referral by priest/spiritual house & 38 & 9.6 \\
\hline Not stated & 26 & 6.5 \\
\hline
\end{tabular}

twenty-three (56.2\%) of the patients were male and 174 (43.8\%) were female. The age range of the patients was $15-75$ years (mean (SD) 31.6 (11.0) years). Other socio-demographic variables for the patients are shown in Table I. Treatment options first employed by patients are shown in Table II. The majority (34.5\%) went to prayer houses, followed by a psychiatric hospital (32.0\%). The reasons for choice of place of first treatment are also shown in Table II; the most common reasons were confidence that they would be well managed at such places (46.3\%) and ignorance of the existence of psychiatric services at the hospital (14.6\%). Most patients eventually selected specialist services after persuasion by friends and relatives (44.8\%) or referral by a health care provider (20.9\%). Table III shows the relationship between the socio-demographic characteristics of the respondents and choice of specialist service as the first-contact caregiver. Male respondents, those with a high level of education, urban dwellers and respondents who attributed illness to a rational cause, employed specialist services as their first-contact caregiver more than others, and this observation was statistically significant. The most common patient perceptions of the cause of their ailment 


\begin{tabular}{|c|c|c|c|c|}
\hline Variable & Yes & No & Total & p-value \\
\hline \multicolumn{5}{|l|}{ Age (yrs) } \\
\hline$<20$ & $14(35 \%)$ & $26(65 \%)$ & 40 & $\chi^{2}=1.83$ \\
\hline $20-29$ & $57(31.7 \%)$ & $123(68.3 \%)$ & 180 & $d f=5$ \\
\hline $30-39$ & $28(28.3 \%)$ & 71 (71.7\%) & 99 & $\mathrm{p}=0.87$ (not significant) \\
\hline $40-49$ & $14(35.9 \%)$ & $25(64.1 \%)$ & 39 & \\
\hline $50-59$ & $8(32.0 \%)$ & $17(68.0 \%)$ & 25 & \\
\hline$>60$ & $6(42.9 \%)$ & $8(57.1 \%)$ & 14 & \\
\hline Gender & & & & $\chi^{2}=10.1$ \\
\hline Male & $86(38.6 \%)$ & $137(61.4 \%)$ & 223 & $d f=1$ \\
\hline Female & $41(23.6 \%)$ & $133(76.4 \%)$ & 174 & $p=0.001$ (significant) \\
\hline \multicolumn{5}{|l|}{ Marital status } \\
\hline Single & $92(33.3 \%)$ & $184(66.7 \%)$ & 276 & $\chi^{2}=4.04$ \\
\hline Married & $24(25.0 \%)$ & $72(75.0 \%)$ & 96 & $d f=2$ \\
\hline Separated/divorced/ & & & & $p=0.13$ (not significant) \\
\hline widowed & $11(44.0 \%)$ & $14(56.0 \%)$ & 25 & \\
\hline \multicolumn{5}{|l|}{ Educational status } \\
\hline No formal education & $5(17.2 \%)$ & $24(82.8 \%)$ & 29 & $\chi^{2}=9.90$ \\
\hline Primary education & $19(21.8 \%)$ & $68(78.2 \%)$ & 87 & $d f=3$ \\
\hline Secondary & $58(36.0 \%)$ & $103(64.0 \%)$ & 161 & $p=0.02$ (significant) \\
\hline Tertiary & $45(37.5)$ & $75(62.5 \%)$ & 120 & \\
\hline Area of residence & & & & $\chi^{2}=16.57$ \\
\hline Urban & $100(39.1)$ & $156(60.9 \%)$ & 256 & $d f=1$ \\
\hline Rural & 27 (19.1\%) & $114(80.9 \%)$ & 141 & $p<0.001$ (significant \\
\hline \multicolumn{5}{|l|}{ Cause of ailment } \\
\hline Rational cause & $62(38.3 \%)$ & $100(61.7 \%)$ & 162 & $\chi^{2}=20.38$ \\
\hline Misconceptions & $22(16.9 \%)$ & $108(83.1 \%)$ & 130 & $d f=2$ \\
\hline Don't know & $43(41.0 \%)$ & $62(59.0 \%)$ & 105 & $p<0.001$ (significant) \\
\hline
\end{tabular}

were demonic and spiritual forces (3 1. 1\%). Other causes included psychological stress (20.6\%), use of 'hard' drugs (12.4\%), poison from perceived enemies (8.3\%), and familial causes $(2.8 \%)$. However, $24.8 \%$ of respondents claimed to be ignorant of the cause of their ailment. Three hundred and sixty-seven $192.4 \%$ expressed satisfaction with their treatment at the hospital.

\section{Discussion}

It is important to understand the choices that people make for treating mental illnesses to ensure proper utilisation of available mental health services, and better management and control of mental disorders. ' This study showed the most common first contact for treatment of mental illnesses to be the prayer house (34.5\%), followed by a psychiatric hospital (32.0\%). Sharma similarly reported a higher preference for spiritualists (38.2\%) than psychiatrists (29.4\%) in his study of treatment-seeking behaviour of mentally ill patients in a rural area in Beri, India. In Nigeria there are still strong beliefs in magico-religious origins of human ailments, especially mental disorders. ${ }^{8}$ The majority of patients in our study attributed their ailments to supernatural causes, which explains why visiting a spiritual house was their first option.

However, male respondents, urban dwellers, those with aboveaverage literacy levels and respondents who held rational views about the causes of mental illness, first consulted specialist psychiatrists more than other respondents. Similar associations

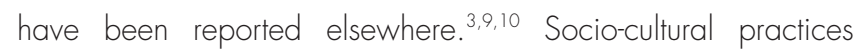
such as male dominance and the stigmatising nature of mental illness (to which women are possibly more susceptible than men) could explain the observed gender difference in healthseeking behaviour of mentally ill patients. ${ }^{10}$ Since the first line of care for the mentally ill constitutes the most important stage of the psychiatric pathway to care, ${ }^{10}$ efforts are needed towards changing the perceptions of patients regarding the cause of their ailments, to encourage early presentation to psychiatric hospitals and prompt treatment. 
Patients' most common reason for the choice of place of first visit was confidence that they would be cured there; this factor has been reported previously? Ignorance of the availability of mental health services was also common among patients. An urgent need therefore exists to increase community awareness about the scope and existence of mental health services and the amenability of mental illnesses to orthodox care, which should lead to positive attitudes that will enhance timely visits to a psychiatrist as well as prompt treatment of conditions.

The most common reason for the eventual visit to a neuropsychiatric hospital was advice by friends/relatives (44.8\%), which demonstrates the role of social networks in decision-making regarding the selection of modality of treatment among mentally ill patients, and is consistent with other reports." ${ }^{71}$ Since the decision of where to seek help involves both patients and relatives, health education efforts should target all members of the community.

\section{Conclusion}

Negative perceptions of the causes of mental illness still abound among mentally ill patients and their relatives. This fact is compounded by ignorance of existing mental health services. Consequently, alternative sources of care are still employed. There is a need for community health education to demystify mental illnesses as well as to highlight the availability of mental health services; this should create positive attitudes, correct misconceptions and encourage early specialist consultation and better treatment outcomes. Mental health services should be made available to rural dwellers by integrating them into existing primary health care services.

We acknowledge the assistance of E Odoh, C N F Ochie, I Okonkwo and E Chukwu for their assistance in distributing the questionnaires used for the survey.

\section{References}

1. Mohammed K, Zubair I, Isa SA, Muktar HA. Perception and beliefs about mental illness among adults in Karfi village, northern Nigeria. BMC Int Health Hum Rights 2004; $4: 3$

2. Murray L, Lopez A. The Global Burden of Diseases - Joint Publication of the World Bank and Harvard University. Cambridge, Mass.: Harvard University Press, 1996: 3-18

3. Fahad A, Fahad S, Hiba R, Kamila H. Relation of gender, education and health seeking behavior of the general population regarding psychiatric illness. J Pak Med Assoc 2006; 56(9): 421-422

4. Gurege O, Chisolm D, Kola L, Lasebikan V, Saxena S. Cost effectiveness of an essential mental health intervention package in Nigeria. World Psychiatry 2007 6(1): $42-48$.

5. Gureje $\bigcirc$. Revisiting the National Mental health Policy for Nigeria. Archives of Ibadan Medicine 2003; 5(1): 2-4.

6. Abdulmalik JO. Psychiatric practice in Nigeria, past, present and future. BMJ West Africa 2007; 10(5): 250-252

7. Sharma P, Vorha AK, Khurana H. Treatment seeking behavior of mentally ill patients in a rural area: A cross sectional study. Indian J Community Med 2007; 32: 290-291.

8. Adebowale TO, Ogunlesi AO. Beliefs and knowledge about aetiology of mental illness among Nigerian psychiatric patients and their relatives. Afr J Med Sci 1999; 28(1-2): 35-4 1 .

9. Banerjee G. Help seeking behavior and belief system. Indian J Soc Psychiatry 1997; 13: 61-64

10. Pradhan SC, Singh MM, Singh RA, et al. First care givers of mentally ill patients: A multicenter study. Indian J Med Sci 200 1; 55(4): 203-208.

1 1. Chadda RK, Aggarwal V, Chandra M. Help seeking behavior of the psychiatric patients before seeking care at a mental hospital. Intern J Soc Psychol 2000; 47: 71 . 78. 